\title{
When Do Rewards Have Enhancement Effects? An Availability Valence Approach
}

\author{
Brian C. Tietje \\ College of Business \\ Cal Poly State University, San Luis Obispo
}

\begin{abstract}
It is commonly argued that although rewards induce behaviors, they undermine attitudes and motivation for subsequent action. This perspective has been applied in a consumer setting to suggest that sales promotions such as coupons will undermine consumer brand evaluations and brand loyalty. Instead of focusing on the undermining effects of promotional rewards, this research applies the availability valence hypothesis (Tybout, Sternthal, \& Calder, 1983) to predict and explain when rewards will enhance recipient response. Two experiments demonstrate that an immediate reward from a product-related source enhances product evaluations by making favorable information more accessible than unfavorable information. Promotions enhance the relative accessibility of favorable information when their benefits are directly experienced and the salience of the promotion's task-contingency is diminished by maximizing consumer behavioral freedom.
\end{abstract}

Almost 30 years ago, Deci (1971) presented empirical evidence that rewards can undermine a person's motivation, attitudes, and behaviors. These findings have significant implications in applied fields such as marketing, because they suggest that promotional rewards such as coupons and rebates undermine product evaluations and brand loyalty (Dodson, Tybout, \& Sternthal, 1978; Scott, 1976). The results also imply that using rewards to encourage prosocial behaviors such as recycling (Diamond \& Loewy, 1991; Witmer \& Geller, 1976), immunizations (Moran, Nelson, Wofford, Velez, \& Case, 1996), weight control (Mavis \& Stoffelmayr, 1994), survey response (Hansen, 1980), and condom acquisition (Dahl, Gorn, \& Weinberg, 1997) might undermine postreward attitudes and motivation. These conclusions leave practitioners with a paradox - consumer rewards may be effective for inducing initial action, but they may have undesirable effects on attitudes and subsequent behaviors.

The primary explanation for undermining effects is based on self-perception theory (Bem, 1972) and attributional discounting (Kelley, 1972). Self-perception and discounting occur when a person relies on past behavior as an informational cue to form an attitudinal judgment, and when behavior is attributed to a reward rather than a positive evaluation of the at- titude object. Research that applied self-perception theory in a consumer context sought primarily to demonstrate empirically how and when rewards undermine product evaluations (Scott \& Yalch, 1978, 1980; Tybout \& Scott, 1983). An important caveat of the self-perception and discounting explanation is that robust undermining effects are obtained only when certain conditions are present (see Cameron \& Pierce, 1994; Tang \& Hall, 1995, for reviews): (a) when insufficient internal cues are available for attitude formation (Eagly \& Chaiken, 1993, pp. 545-546; Fazio, Powell, \& Williams, 1989; Tybout \& Scott, 1983; Wood, 1982), (b) both the reward and its task-contingency are salient (Ross, 1975; Ryan, Mims, \& Koestner, 1983), and (c) there is sufficient initial interest in the behavior to accommodate undermining (Calder \& Staw, 1975; Hitt, Marriott, \& Esser, 1992; Lepper, 1998; Lepper, Greene, \& Nisbett, 1973).

A number of studies demonstrate that in the absence of any one of these conditions, undermining does not occur and rewards instead have positive effects. When persons have existing knowledge or experience with a product (Tybout \& Scott, 1983; Wood, 1982), product evaluations are higher in the presence versus absence of a reward. Rewards also enhance recipient response when a reward or its task-contingency is not salient during attitude formation. For example, Ross (1975) obtained enhancing effects by distracting participants from considering the reward during their performance of the rewarded task. Kruglanski et al. (1975) demonstrated that rewards have positive effects on intrinsic motivation when re- 
wards are inherent to a task (e.g., a coin-toss game) and not considered an extrinsic inducement. Enhancement effects are also obtained when rewards are performance contingent (i.e., reward given for a specific level of performance) or task noncontingent (reward given regardless of behavior; Eisenberger \& Cameron, 1996; Ryan et al., 1983) or when they provide feedback concerning a recipient's competence or self-determination (Deci, 1971; Harackiewicz, 1979; Pittman, Davey, Alafat, Wetherill, \& Kramer, 1980; Rosenfield, Folger, \& Adelman, 1980; Ryan et al., 1983). Finally, enhancement effects have been obtained when individuals are rewarded for performing uninteresting tasks (Calder \& Staw, 1975; Hitt et al., 1992; Newman \& Layton, 1984).

Why enhancement would occur in these conditions is not certain. When the preconditions for self-perception and discounting do not occur, what psychological processes take place? In this research, I propose that availability valence (Hannah \& Sternthal, 1984; Tybout et al., 1983) delineates the psychological processes that lead to both undermining and enhancement effects.

\section{AVAILABILITY VALENCE}

Availability valence (Hannah \& Sternthal, 1984; Kisielius \& Sternthal, 1984; Tybout et al., 1983) is a memory-based approach with the central hypothesis that "individuals' attitudinal judgments in response to a persuasive message are determined by the favorableness - or valence-of the issue-relevant information available in memory at the time of judgment" (Hannah $\&$ Sternthal, 1984, p. 633). Availability valence was used to rectify conflicting effects in the multiple request compliance literature by predicting that compliance with a second request is enhanced only when favorable information is more available at the time of the compliance decision than any unfavorable information (Tybout et al., 1983). Favorable information in a multiple request context includes an individual's own compliance with an initial request in the foot-in-the-door scenario and a requestor's concessionary behavior in the door-in-the-face scenario. Unfavorable information in a multiple request context includes an individual's rejection of an initial request in the door-in-the-face scenario or a requestor's escalation of his or her demands in the foot-in-the-door scenario.

The availability valence hypothesis integrates concepts from several theories, including self-perception (Bem, 1972), attribution (Kelley, 1972), cognitive evaluation (Deci \& Ryan, 1985), equity (Gouldner, 1960), and reactance (Brehm, 1966), to explain and predict the attitudinal and motivational effects of rewards. The availability valence approach works well to complement, rather than supercede, these theories. ${ }^{1}$ Self-perception (Bem, 1972), for example, provides a theoretical ac-

\footnotetext{
${ }^{1}$ The author thanks an anonymous reviewer for this suggestion.
}

count of how information obtains a favorable or unfavorable valence, and availability valence explains how this evaluative information affects attitudes and compliance. Prior behavior that is attributed primarily to a reward is perceived as unfavorable, whereas behavior that is perceived to be a reflection of one's true attitude is favorable. The availability valence hypothesis is also consistent with cognitive evaluation theory (Deci \& Ryan, 1985). When events are influenced and controlled by extrinsic factors such as rewards, the perceived locus of causality is external, and undermining occurs. "Controlling events are hypothesized to stifle creativity, diminish cognitive flexibility, yield a more negative emotional tone, and decrease self-esteem, relative to events that support autonomy" (Deci \& Ryan, 1985, p. 63). Cognitive evaluation theory (Deci \& Ryan, 1985, p. 64) can be reinterpreted using availability valence to suggest that intrinsic motivation for a task is impacted by the relative salience (= availability) of the controlling (= unfavorable) versus informational (= favorable) aspects of a reward. When the controlling dimensions of a reward are more salient than its informational aspects, the reward will undermine intrinsic motivation. When the informational dimensions of a reward are more salient, the reward will enhance intrinsic motivation.

Availability valence also provides insights on how to make favorable information more salient than unfavorable information (Hannah \& Sternthal, 1984; Kisielius \& Sternthal, 1984; Tybout et al., 1983). More recently processed information is retrieved from memory more readily than is more distal information, particularly when memory is accessed soon after learning. Information related to oneself is more readily available than is information related to someone else (Rogers, Kuiper, \& Kirker, 1977), and more substantial information (e.g., compliance with a substantial versus small request) is more readily available than less substantial information due to the greater number of associations and linkages in memory for such behavior (Bower, 1972).

To test this theory, Tybout et al. (1983) manipulated the favorableness of information available for a judgment task by having either an authoritative person (favorable condition) or the participant's peer (unfavorable information) make a request (an operationalization suggested in Thibaut \& Reicken, 1955). The type of information that was most available in memory was manipulated by having participants view a TV monitor during the study that displayed either themselves or the experimenter who presented the requests. As predicted, the favorable request information (concession) enhanced compliance relative to unfavorable request information (escalation) only when the participant viewed the requestor's favorable, concessionary behavior on the TV monitor.

Given the earlier proposition that the recency of favorable and unfavorable information affects its encoding and accessibility in memory, it is plausible that the timing of a reward will moderate its effects. The timing of a promotional reward is managerially relevant because it differentiates promotions that are redeemed immediately at the point-of-purchase (e.g., instant-redeemable coupons), versus those which require con- 
sumers to wait for a subsequent purchase or even longer for eventual redemption (e.g., mail-in rebates).

Consider an "immediate" promotional reward such as an instant coupon in which the consumer receives the benefits of the reward prior to consumption. In a new product trial context, such an occurrence would mean that the consumer derives benefits from the reward before forming an attitudinal judgment about the promoted product. In this research, I propose that a promotional reward distributed before a consumer evaluates a product (hereafter referred to as an immediate reward) provides favorable information about the reward, reduces consumer reactance, and enhances the evaluation of the product relative to a no-reward baseline condition. Delaying a reward's distribution-promising the reward prior to the evaluation, but distributing it after the evaluative task is performed-will enhance the salience of the reward's task-contingency and its controlling aspects and subsequently undermine product evaluations relative to a no-reward condition.

H1: Persons who receive a reward before they evaluate a product will report higher product evaluations than persons who receive no reward for their product choice.

H2: Persons who are promised a reward before, but receive a reward after they evaluate a product will report lower product evaluations than persons who receive no reward for their product choice.

\section{METHOD}

\section{Study 1}

Overview. To demonstrate both undermining and enhancement effects on product evaluations, an experiment was conducted in which participants made a choice between two brands of carbonated beverages, and were randomly assigned to receive either no reward, an immediate reward, or a delayed reward for selecting the focal brand. The participants reported taste evaluations and purchase intentions toward their brand choice.

Participants. A total of 237 students at a major West Coast university participated in the study as one of their options to fulfill requirements for an undergraduate marketing course. Each treatment condition was administered across several sessions, and there were no significant differences in any of the dependent measures across different sessions of the same condition. ${ }^{2}$

\footnotetext{
${ }^{2}$ The no-reward condition was administered in six groups with an average size of 14 , the immediate-reward condition was administered in three groups with an average size of 21 , and the delayed-reward condition was administered in five groups with an average size of 13 .
}

Design and procedure. Participants were told by a moderator that a beverage manufacturer was introducing a new brand of seltzer water and wanted to obtain consumer reactions to it. They were told that they could taste "a new brand of seltzer water made with special natural ingredients designed to give it a great taste." The participants were given a choice and were told the following: "If for some reason you did not wish to try the new brand, you can try an alternative store brand instead." The new brand was a national brand of seltzer water whose label was concealed by masking tape. The store brand's label was unconcealed. No other product information was provided.

Due to resource constraints, the author, who was aware of the hypotheses, was one of the moderators who administered the study. To reduce the potential for demand artifacts, the experimental procedure was described in a written script that was read verbatim to participants. Special emphasis was placed on avoiding eye contact with participants or varying voice inflection while the instructions were read.

Ten participants chose not to sample the new brand, and their data were not used in the analysis. The choice scenario was structured so that participants had the freedom to choose either brand, but the implicit superiority of the new focal brand versus the store brand guided the majority of participants to select the focal brand. This design is not intended for testing the effect of a reward on initial choice, but rather to reduce the potential for self-selection bias. In this manner, the impact of the reward on subsequent product evaluations and purchase intentions could be isolated from any systematic individual differences.

After receiving the relevant product information, participants in both the immediate- and delayed-reward conditions were told the following: "In order to maximize the number of persons who taste the new brand, the manufacturer is offering an extra incentive. Everyone who agrees to try the new brand will also receive a 1 dollar bill." A dollar bill was used as the reward instrument because it was presumed to have a fairly consistent value to all recipients, and its value would be considered sufficient to influence choice. Questionnaires were distributed, and participants were asked to indicate their brand choice in their booklets. In the immediate-reward condition, participants received $\$ 1$ immediately after making their choice to sample the new brand. In the delayed-reward condition, participants who agreed to sample the new brand of seltzer water were told that they would receive $\$ 1$ at the conclusion of the study. In the no-reward condition, participants were not offered a reward for their brand choice.

Measures. A 5-item product evaluation measure was obtained 2 times during the experiment-after receiving the experimental treatment information but before tasting the product, and after tasting the product. The five items were each measured on a scale ranging from -5 to +5 , anchored with not desirable-desirable, bad tasting-good tasting, not 
satisfying-satisfying, not refreshing-refreshing, and low quality-high quality. Participants were first asked to evaluate their chosen brand before tasting it, based on their expectations of the product and the information available to them at that time. Participants then evaluated the product after tasting a 6-ounce sample.

Participants also responded to single item measures of purchase intentions, satisfaction with the product, and overall satisfaction with the tasting study itself, all on a scale of 1 to 10. In the delayed-reward condition, participants received their dollar after they completed all of these measures and the booklets were collected.

A second experimental booklet was distributed in the delayed-reward condition, after the reward was distributed. In this booklet, participants were asked to evaluate the product again using the same 5-item scale as before, and to retrospectively indicate how confident they were that they would actually receive the dollar reward, using a single item confidence scale with 1 indicating not at all confident and 10 indicating very confident. The postreward evaluations were captured to determine if participants in the delayed-reward condition altered their consumption-based product evaluations after receiving the reward. The confidence measure was taken to determine whether participants in the delayed-reward condition were skeptical that they were going to actually receive the promised reward.

A direct measure of attitude toward the reward was not included for two reasons. First, the theoretical explanation in this study does not rely on a mediation process in which a reward characteristic such as timing impacts attitude toward the reward, which in turn influences product evaluations. Thus, the effect of the experimental manipulation on attitudes toward the reward is of secondary concern. Second, there was concern that including a direct measure of reward evaluations might unintentionally reveal that the reward was a focal element in the study, and trigger demand artifacts such as a bias in participant reactions (Shimp, Hyatt, \& Snyder, 1991).

Study 1 results. Due to unequal sample sizes, planned contrasts that do not assume equal variances among the treatment groups were used to test the hypotheses (Maxwell \& Delaney, 1990). Although both pretaste and posttaste product evaluations were obtained, the primary dependent variable for analysis was the mean score of the 5-item posttaste product evaluation scale (Cronbach $\alpha=.96$ ), because this evaluation was based on direct product experience. ${ }^{3}$ Consistent with

\footnotetext{
${ }^{3}$ Pretaste evaluations exhibited a similar pattern as posttaste evaluations, but direct product experience contributed to more substantive differences. Pretaste evaluations in the no-reward condition were directionally but not significantly lower compared to the immediate-reward condition (no reward $=0.62, S D=2.15$; immediate $=1.06, S D=1.71), t(147)=1.39, p=.17$, but were significantly higher than the delayed-reward condition (delayed $=$ $-0.12, S D=2.33), t(169)=2.15, p=.03$.
}

H1, the immediate-reward enhanced product evaluations. Product evaluations in the immediate-reward condition were significantly higher compared to the no-reward condition (immediate $=1.35, S D=2.57$; no reward $=0.29, S D=2.98$ ), $t(146.4)=2.34, p=.02$, and the delayed-reward condition (delayed $=-0.66, S D=2.89), t(145.0)=4.51, p<.0001$. Consistent with $\mathrm{H} 2$, evaluations in the delayed-reward condition were lower than the no-reward condition, $t(169.8)=2.12, p=$ .04 (see Figure 1).

Purchase intentions exhibited similar directional patterns, but did not approach statistical significance. Purchase intentions in the immediate-reward condition $(3.88, S D=2.86)$ were not significantly higher than in the no-reward condition (3.09, $S D=2.58), t(129.8)=1.7, \mathrm{p}=.09$, and they were not lower in the delayed-reward condition $(2.78, S D=2.47)$ than in the no-reward condition, $t(74.7)=1.2, \mathrm{p}=.24$. The single-item measure of product satisfaction, however, did obtain significance in a consistent pattern with product evaluations. Product satisfaction was higher in the immediate-reward condition $(5.91, S D=2.57)$ than in the no-reward condition (4.85, $S D=2.17), t(143)=2.07, \mathrm{p}=.04$, and lower in the delayed-reward condition $(3.88, S D=2.42)$ than in the no-reward condition, $t(71.4)=3.04, \mathrm{p}=.003$.

In contrast to the other dependent measures, participants' overall satisfaction with the study was higher in the immediate-reward condition $(7.58, S D=1.88)$ than in the no-reward condition $(5.43, S D=2.80), t(147.1)=5.65, p<.0001$, and directionally higher in the delayed-reward condition $(6.22, S D$ $=2.68)$ as compared to the no-reward condition, $t(169.7)=$ $1.89, p=.06$. When asked, "How satisfied were you overall with the taste test study itself?", participants in both reward conditions reported greater satisfaction with the study than participants in the no-reward condition.

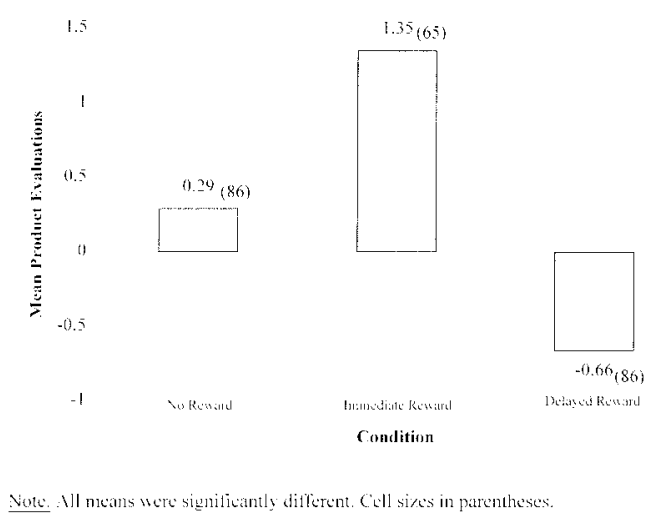

FIGURE 1 Study 1 mean posttaste evaluations. 
As indicated previously, participants in the delayed-reward condition responded to a second posttaste evaluation measure after receiving their reward. Participants' postreward product evaluations in the delayed-reward condition were lower than immediate-reward participants' posttaste evaluations (delayed $=-0.45, S D=2.92$; immediate $=1.35, S D=2.57), t(89.0)=3.36, p=.0011$, but were not significantly lower than no-reward participants' posttaste evaluations, $t(93.8)=1.37, p=.17$.

Study 1 discussion. Consistent with the hypotheses based on availability valence, the immediate reward in this experiment enhanced product evaluations and the delayed reward undermined evaluations, both relative to a no-reward baseline condition. The explanation of these results based on availability valence is that the immediate reward made favorable information about the reward salient at the time of evaluative assessment, thus enhancing product evaluations. The delayed reward made the task-contingency of the reward most salient, providing unfavorable information that led to less positive evaluations of the product.

An alternative hypothesis based on these results is that the reward timing manipulation triggered a positive mood effect for recipients of the immediate reward, and a negative mood effect for recipients who were frustrated by the delayed reward. Because mood is pervasive (Isen, Clark, Shalker, \& Karp, 1978), an affect-based explanation would predict that all of the evaluative measures would exhibit a similar pattern of enhancing effects for the immediate reward and undermining effects for the delayed reward. However, results from the study provide evidence that is inconsistent with this affect-based explanation. In contrast to the other dependent measures, participants' overall satisfaction with the study was higher in both the immediate and delayed-reward conditions as compared to the no-reward condition. These results suggest that the undermining effects from the delayed reward were directed only toward the product, and not global effects such as those induced by mood or affect (Isen et al., 1978).

Further, an affect-based explanation would suggest that when participants receive the reward, their momentary affective state is enhanced, and they are more inclined to respond favorably to the product (Gorn, Goldberg, \& Basu, 1993; Isen et al., 1978). This explanation would suggest that after receiving the reward at the end of the study, delayed-reward participants would also exhibit enhancement. Contrary to this prediction, however, product evaluations in the delayed-reward condition remained relatively unfavorable even after participants received their reward.

Another alternative explanation for the undermining effects in the delayed-reward conditions is that participants felt deceived and did not think they were going to receive a reward. Results are also inconsistent with this explanation. Participants in the delayed-reward condition reported a fairly high retrospective confidence that they would actually receive the prom- ised reward. When asked, "How confident were you that you would actually receive the dollar?" participants reported an average confidence rating of 6.8 on a scale of 1 to $10(1=$ not at all confident, $10=$ very confident , with $72 \%$ of the participants reporting a confidence of 6 or higher. Although retrospective biases may have inflated these subjective assessments (e.g., hindsight bias; Fischhoff, 1975), the results indicate that participants believed that they would receive the reward as promised. Furthermore, if participants felt they were being duped, it is likely they would have reported poor satisfaction with the study overall. However, both the delayed- and immediate-reward participants were more satisfied with the study than their no-reward counterparts.

Although Study 1 obtained results that are consistent with the availability valence explanation, Study 2 was designed to test the explanation more directly. Availability valence predicts that attitudinal judgments are determined by the valence of issue-relevant information that is available at the time of judgment. In Study 1, the source of the reward was product-related (the manufacturer), therefore the immediate reward provided favorable information that was issue-relevant. If the immediate reward came from a source unrelated to the product, the reward would not be product-relevant, would therefore not be used by consumers to form evaluative assessments, and would not enhance product evaluations.

To test this explanation, both the source of the reward and its timing are manipulated in Study 2, and a reward timing $\times$ source interaction is hypothesized. Specifically, an immediate reward given by a product-related source will enhance product evaluations relative to an immediate reward given by a source unrelated to the product.

H3: Persons who receive an immediate reward from a source related to the product will report higher product evaluations than persons who receive an immediate reward from a source unrelated to the product.

The impact of manipulating the source of the reward in the delayed-reward condition is less predictable based on prior theory. One hypothesis is that regardless of its source, the delayed reward will consistently undermine product evaluations because of its salient task-contingency. Because the consumer who is offered a delayed reward does not receive the benefits of the reward before initially evaluating the product, the source of the reward may not matter. However, knowing that a promotional reward is being offered by a source unrelated to the product versus a product-related source may impact consumer reaction to the promised reward. In Study 1, the delayed reward undermined product evaluations because it made unfavorable information about the reward's task-contingency salient during attitude formation. A previously unstated assumption of this explanation is that the unfavorable information provided by the reward was considered relevant and attributable to the product and consequently impacted product evaluations. If the source of the reward is unrelated to 
the product, the delayed reward's salient task-contingency would no longer be perceived as unfavorable issue-relevant information and would therefore no longer undermine product evaluations. Thus, I propose that a delayed reward from a source related to the product will obtain less favorable product evaluations than a delayed reward from an unrelated source.

H4: Persons who receive a delayed reward from a source related to the product will report lower product evaluations than persons who receive a delayed reward from a source unrelated to the product.

\section{Study 2}

Overview. Participants in this experiment received a reward either from the manufacturer or an independent marketing research firm to test whether the source of the reward moderates the reward timing effect. Experimental procedures and measures were similar to those used in Study 1. As in Study 1, the experimental procedure was described in a written script that was read verbatim to participants. One of two individuals served as moderators during Study 2-the author who was aware of the hypotheses and a colleague who was not. Resource constraints necessitated the author's participation. A dummy code for moderator did not approach significance in any of the analyses reported in this study.

Participants. A total of 257 students at a major West Coast university participated in the study to fulfill requirements for an undergraduate marketing course.

Design and procedures. Groups of 5 to 25 participants were randomly assigned to one of four treatment conditions corresponding to a 2 (immediate, delayed-reward timing) $\times 2$ (reward from manufacturer or an independent marketing research firm) factorial design. As in Study 1, each treatment condition was administered across several sessions, and there were no significant differences in the dependent measures across different sessions of the same condition. ${ }^{4}$

The study used the same experimental context and procedures as Study 1, where a beverage manufacturer was introducing a new seltzer product and wanted to study consumer reactions to it. Nine participants chose not to sample the new

\footnotetext{
${ }^{4}$ The number of experimental sessions that included each treatment condition are as follows, with average group size in parentheses: no reward-3 (25); immediate reward from manufacturer - 3 (20); immediate reward from marketing research firm-2 (17); delayed reward from manufacturer-2 (26); and delayed reward from marketing research firm-2 (19).
}

brand, and, as in Study 1, their data were not used in the analysis.

The conditions in Study 1 were replicated in one half of Study 2, in which participants were told that the reward was provided by the manufacturer. In contrast, participants in both the immediate-from-market-research-firm and delayed-from-market-research-firm reward conditions were told the following: "In order to maximize the number of people who taste the new brand, an independent marketing research company is offering an extra incentive. Everyone who agrees to try the new brand will also receive a 1 dollar bill from the independent marketing research company." To make the source of the reward salient, an adhesive label was placed on the dollar bills displaying either the words "Compliments of the New Brand's Manufacturer" or "Compliments of the Independent Marketing Research Firm." While distributing the dollar bills, the moderator told the participants the following:"Please keep in mind that the independent marketing research company that is offering the reward is not affiliated in any way with the brands being tested, or with the manufacturer of any brands in the product category." Identical procedures were used as in Study 1 for the reward timing manipulation.

Measures. In Study 2, after completing the same measures of product evaluations, purchase intentions, satisfaction with the product, and satisfaction with the study as were used in Study 1, participants responded to two additional measures. First, a manipulation check was used to determine participants' accuracy in remembering the source of the reward they received. Participants were given a list of several options to select to indicate their recall of the reward source: "The store brand's manufacturer," "The new brand's manufacturer," "An independent marketing research firm," "I can't remember," and "Other."

A second additional measure was a thought-listing task in which participants were asked to write down all the thoughts they had either during the study or at the present time about the product(s), the study itself, or anything else that came to mind. Participants were told to take about $10 \mathrm{~min}$ for the exercise, and sufficient room for eight comments was provided in the survey booklet.

Coding categories. Following Wright (1980), categories of participant thoughts were developed using three referents - the theory on which the experiment was designed, prior studies involving the impact of rewards on product evaluations (Scott \& Yalch, 1980), and an informal content analysis of participant comments. The following coding categories were used:

- The Reward itself and the Source of the Reward-The experiment manipulated both the timing and the source of the 
reward, so positive, negative, and neutral thoughts about the reward itself were placed in one category (e.g., "It was nice to receive a dollar for participating"), and thoughts about the source of the reward were placed in another (e.g., "The independent marketing research firm made the study enjoyable by giving out money").

- Attributions-In their experiment using rewards, Scott and Yalch (1980) included attribution measures to determine the extent to which participants consciously attributed their brand choice to either internal or external factors. An explicit measure of attributions was not used in this study because of demand artifact concerns (Shimp et al., 1991), but a category was generated to capture thoughts that attributed brand choice either to internal (e.g., "I like tasting new products, so I chose the new brand") or external factors (e.g., "I chose the new brand because of the dollar").

- Brand-Because product evaluations were the primary dependent variable in the study, positive, negative, and neutral thoughts regarding the brand were also categorized (e.g., "This new brand of seltzer tastes better than the other brands I've tried before").

- Product Category-An informal analysis of the thoughts generated in the study revealed a large number of comments about the product category. Seltzer water was used in the study because it was presumed that participants would have limited experience with the product and would therefore possess fairly malleable attitudes toward brands in this category. Many participants commented about the category choice, both from a positive (e.g., "I like seltzer water") and negative (e.g., "I do not like seltzer water and probably never will") perspective.

- Other Thoughts-This includes comments, suggestions, and criticisms relating to the study and its implementation (e.g., "This study should let us taste the other for comparison"), and the evaluation task (e.g., "The questionnaire before tasting was hard to judge because there's no basis for the answers").

Two independent coders were instructed on the content of the categories and categorized each response. The coders also judged whether the comments were positive, negative, or neutral, as participants were not instructed to do so on their own to minimize respondent fatigue.

Study 2 results and discussion. As in Study 1, the primary dependent variable was the mean score of the 5-item posttaste product evaluation scale (Cronbach $\alpha=.96)$. The results replicated those from Study 1, in which product evaluations were higher when an immediate reward was given by the manufacturer $(1.78, S D=2.48)$ compared to a delayed reward $(-0.48, S D=2.66), t(99.4)=4.54, p<.0001$. Moreover, consistent with both hypotheses for Study 2, there was a significant reward timing $\times$ source interaction, $F(1,173)=19.69, p<$
.0001 (see Figure 2). H3 predicted that the immediate reward from the manufacturer would enhance product evaluations relative to the immediate reward from the market research firm. Consistent with $\mathrm{H} 3$, product evaluations in the immediate-reward-from-manufacture $r$ condition were higher than those in the immediate-reward-from-marketing-research-firm condition $(0.32, S D=2.82), t(59.6)=2.49, p=.02$.

$\mathrm{H} 4$ predicted that the delayed reward from the manufacturer would undermine product evaluations, relative to the delayed reward from the marketing research firm. Consistent with $\mathrm{H} 4$, evaluations in the delayed-reward-from-manufacturer condition were lower than those in the delayed-reward-from-marketing- research-firm condition $(1.63, S D=$ 2.53), $t(77.6)=3.72, p=.0004$.

The pattern of results for the other dependent measures, including purchase intentions and satisfaction with the product, were consistent with the product evaluation scores. That is, purchase intentions and satisfaction with the product showed a similar timing $\times$ source interaction. However, significant differences across treatment conditions were not obtained (reward timing effect for the satisfaction with the study measure was $F[1,173]=.71, p=.40$; reward source effect, $F[1$, $173]=.02, p=.88$; timing $\times$ source interaction, $F[1,173]=$ $1.58, p=.21$.

The reward source manipulation was effective, as $73.6 \%$ of the participants were able to accurately recall the source of the reward they received. A greater proportion of participants in the immediate-reward condition accurately recalled the source $(88.2 \%)$ compared to participants in the delayed-reward condition $(57.6 \%), \chi^{2}(1, N=248)=22.05, p<.0001$. Those who received an immediate reward were more accurate because they could view their dollar with the correspond-

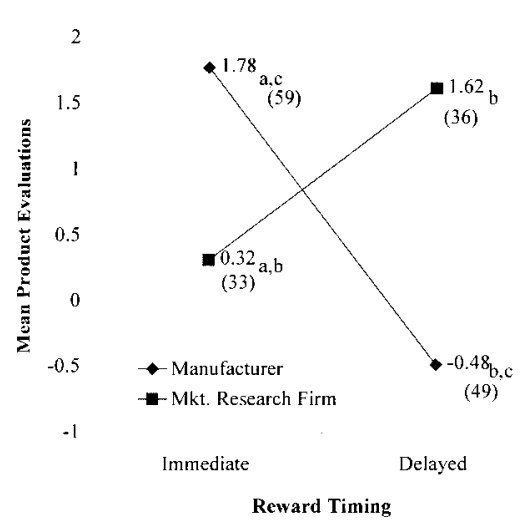

Note. Values with equivalent subscripts indicate significant differences. Cell sizes are in $\overline{\text { parentheses. }}$ 
ing labels: "Compliments of the new brand's manufacturer/the independent marketing research firm" while responding to the recall question. Participants also had a more difficult time accurately recalling the source when the reward came from the marketing research firm $(65.2 \%)$ versus the manufacturer $(78.9 \%), \chi^{2}(1, N=248)=4.01, p=$ 0.045 . Because most promotions tend to come from manufacturers, the recall accuracy patterns exhibit ecological validity. An analysis of the data excluding participants who mistakenly attributed the reward to the incorrect source did not yield a different pattern of results than were previously reported.

Results from the thought-listing data provide insights regarding the psychological processes that occurred during the experiment and their influence on the dependent measures. Participants generated 1,338 responses $(M=5.2, S D=1.8)$, with a range of 0 to 9 thoughts per respondent. Initial interjudge agreement $(1,128$ out of 1,338$)$ was $84 \%$ and the index of reliability was .91 (Perreault \& Leigh, 1989). Because of physical and temporal separation between the two coders, disagreements could not be resolved via discussion. Instead, the comments under debate were randomly ordered so that their respective experimental conditions were not known, and the author resolved the disagreements and made the final determinations for coding. The proportion of responses that were classified into each of the coding categories follows: Reward-5.5\%, Reward Source-1.1\%, Attributions-14.2\%, Brand-33.3\%, Product Category-21.1\%, and Other Thoughts-24.8\%. Neutral comments accounted for $33.6 \%$ of the total listed thoughts.

Participants were less likely to acknowledge internal factors as a reason for their brand choice when they received an immediate reward compared to a delayed incentive. Participants recorded a significantly lower number of internal attribution thoughts (i.e., attributing their brand choice to factors such as curiosity) in the immediate-reward condition $(M=$ $.24, S D=.46)$ than in the delayed-reward condition $(.55, S D=$ $.66), F(1,178)=12.8, p=.0004$. However, no significant difference was obtained between the number of external attributions that were made in the immediate-reward condition $(M=$ $.38, S D=.53)$ versus the delayed-reward condition $(.31, S D=$ $.46), F(1,178)=1.1, p=.29$. The source of the reward did not yield differences in the pattern of either internal or external attributions, and there was not a significant timing $\times$ source interaction. These results suggest that the immediate reward tended to diminish internal attributions, but did not significantly increase external attributions to the same degree. This analysis also suggests that the effect of the experimental manipulations on product evaluations cannot be accounted for with an approach that relies on attributions.

To accommodate compensatory judgment in which participants' positive thoughts are balanced against negative thoughts, a net thought score was calculated by subtracting the number of negative thoughts in a given coding category from the positive responses (Wright, 1980). Participants' net thoughts of the reward, the reward source, the brand, and the product category were all calculated in this manner. In addition, an overall net thought score was generated for each participant by subtracting the total number of negative thoughts across all categories from the total number of positive thoughts.

The explanation based on availability valence theory is that a reward's timing and source affect the relative accessibility of favorable versus unfavorable information, which in turn impacts product evaluations. This explanation suggests mediation, in which the experimental manipulations affect net thoughts, and net thoughts impact product evaluations. The main effect for reward timing and source and the timing $x$ source interaction were operationalized using effects coding (Neter et al., 1990), and a three-step regression analysis to test for mediation was used, with the experimental treatments as independent variables, the overall net balance of positive versus negative thoughts as the mediator, and product evaluations as the dependent variable (Baron \& Kenny, 1986, see Table 1). For simplicity, coefficients for the main effects are not provided because the timing $\times$ source interaction was the significant factor of interest.

Baron and Kenny (1986) suggested that mediation occurs when three conditions are met: the independent variable affects the mediator, the independent variable affects the dependent variable, and the mediator affects the dependent variable when the independent variable is also included as a predictor. As Table 1 indicates, the timing $\times$ source interaction had a significant effect on the overall net balance of positive versus negative thoughts $(\beta=.22, p=.034)$ and product evaluations $(\beta=.90, p<.0001)$. Furthermore, the effect of the

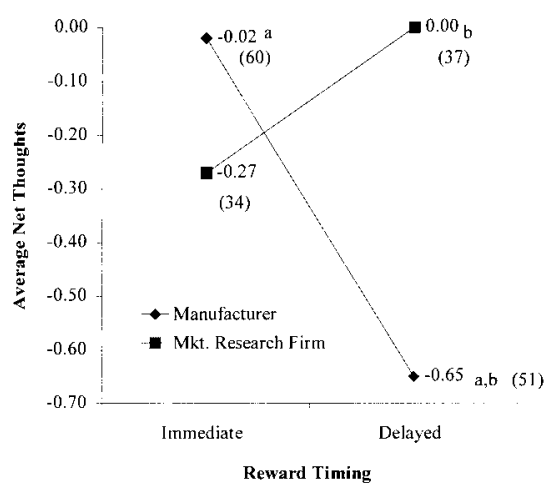

Note. Includes the average number of positive less the number of negative thoughts about the reward, reward source, brand, and product category. Values with equivalent subscripts indicate significant differences. Cell sizes are in parentheses.

FIGURE 3 Net thoughts across experimental conditions. 
TABLE 1

Mediation Analysis 1(Reward manipulation $\rightarrow$ Net Thoughts $\rightarrow$ Product Evaluations)

\begin{tabular}{|c|c|c|c|c|}
\hline Model & Variable & Unstandardized $\beta$ & $t$ & $p$ \\
\hline Effect of interaction on net thoughts & Timing $\times$ source interaction & .22 & 2.14 & .034 \\
\hline Effect of interaction on product evaluations & Timing $\times$ source interaction & .90 & 4.55 & $10^{-6}$ \\
\hline \multirow[t]{2}{*}{ Effect of interaction and net thoughts on product evaluations } & Timing $\times$ source interaction & .67 & 4.04 & $10^{-5}$ \\
\hline & Net thoughts & 1.07 & 9.04 & $10^{-16}$ \\
\hline
\end{tabular}

Note. Analysis follows the three-step process delineated by Baron and Kenny (1986).

TABLE 2

Mediation Analysis 2 (Net Thoughts $\rightarrow$ Product Evaluations $\rightarrow$ Purchase Intentions)

\begin{tabular}{llrl}
\hline Model & Variable & Unstandardized $\beta$ & $t$ \\
\hline Effect of net thoughts on product evaluations & Net thoughts & 1.15 & 10.9 \\
Effect of net thoughts on purchase intentions & Net thoughts & .90 & $10^{-23}$ \\
Effect of net thoughts and product evaluations on purchase intentions & Net thoughts & .43 & 9.29 \\
& Product evaluations & .39 & $10^{-18}$ \\
\hline
\end{tabular}

timing $\times$ source interaction on product evaluations remained significant, but was diminished when net thoughts were added to the model $(\beta=.67, p<.0001)$. These results are consistent with mediation (Baron \& Kenny, 1986), but not perfect mediation because the coefficient for the timing $\times$ source interaction was still significant in the third equation. The pattern of net thoughts is also similar to product evaluations (compare Figures 2 and 3). Net thoughts were higher, for example, in the immediate-reward-from-manufacturer condition $(-.02, \quad S D=1.35)$ than in the delayed-reward-from-manufacture $\mathrm{r}$ condition $(-.65, S D=$ $1.04), t(108)=2.78, p=.006$.

These results provide evidence that the effect of the reward timing $\times$ source interaction on product evaluations was mediated by the net balance of positive versus negative thoughts that participants expressed during the verbal protocol.

Another stage of mediation was tested to determine if the effect of participants' thoughts on purchase intentions was mediated by product evaluations (see Table 2).

Consistent with mediation, the effect of the net balance of positive versus negative thoughts on purchase intentions was significant $(\beta=.90, p<.0001)$, but this effect was attenuated when product evaluations were added to the model $(\beta=.43, p$ $<.0001)$. Further analysis revealed that brand-related thoughts were completely mediated by product evaluations. The unstandardized regression coefficient dropped from .87 $(p<.0001)$ when purchase intentions were regressed on brand-related thoughts (i.e., equation 2) to $.25(p=.08)$ in equation 3 when purchase intentions were regressed on both brand-related thoughts and product evaluations (all other conditions for mediation were attained). The results of these analyses are consistent with the explanation based on availability valence. The timing and source of the reward impacted the amount of favorable versus unfavorable information that was accessible for evaluative assessment, as predicted by availability valence, and the net balance of thoughts significantly affected product evaluations. Furthermore, the effect of these thoughts on purchase intentions was mediated by product evaluations.

\section{DISCUSSION}

Since Deci's early empirical demonstration of undermining effects (1971), a voluminous quantity of research has attempted to further demonstrate and explain them. Perhaps undermining captured such interest because of its counterintuitive implications. When deCharms (1968) suggested that paying a worker might undermine motivation and withholding pay might enhance motivation, he himself called the idea "ridiculous" (p. 329). Although practitioners do wish to avoid undermining, an even more important consideration is how to generate enhancement effects. In a consumer marketplace where 249 billion coupons were distributed in 1998 alone (NCH Nuworld Marketing Limited, 1999), marketers are challenged to leverage the pervasive use of consumer rewards in a positive fashion. Consistent with recent literature in social psychology (Eisenberger \& Cameron, 1996; Eisenberger, Pierce, \& Cameron, 1999), this research demonstrates that undermining effects need not occur, and enhancement effects can be obtained in conditions that are neither restrictive nor unrealistic.

In their article comparing alternative approaches to research activities, Greenwald, Leipe, Pratkanis, and Baumgardner (1986) described the method of condition seeking. Using this method, researchers avoid overgeneralizing empirical findings 
by seeking to identify the specific conditions when a particular phenomenon occurs, rather than trying to conclusively "prove" an effect. This study employed the method of condition seeking to identify two key factors that determine when rewards enhance or undermine product evaluations: a reward's timing and a reward's source. Results from two separate experiments demonstrate that an immediate reward given by a product-related source enhances product evaluations, whereas a delayed reward undermines evaluations. The finding that the source of the reward moderates the enhancement effect from an immediate reward not only demonstrates when enhancement will or will not occur, but also provides a theoretical account for the psychological processes that lead to enhancement. Consistent with availability valence, an analysis of the thoughts generated in Study 2 indicate that the timing and source of a reward impact the relative amount of favorable information that is accessible during the evaluative process. Prior research that focused primarily on the deleterious effects of rewards on intrinsic motivation and other manifestations of recipient response provides a rich description of rewards' undermining effects. The theoretical approach presented in this study advances our understanding of rewards' undermining and enhancing effects.

Future research can build on these findings and address some of the limitations of these studies. Future studies can be implemented in a field setting with manipulations that more closely match those used in the marketplace. Ongoing tracking measures can be used to monitor changes in evaluations over a broader time span to assess the effect of rewards on consumers' short- and long-term evaluative assessments, and to address possible concerns that demand effects introduced bias in these studies. Also, direct measures of mood and other dimensions of consumer response should be included to provide a more direct test that the impact of rewards on product evaluations is not based purely on affect manipulation. These refinements will strengthen the current evidence in support of the availability valence explanation of reward enhancement effects.

\section{ACKNOWLEDGMENTS}

The author thanks dissertation chair Richard Yalch and committee members Anthony Greenwald, Therese Louie, Dorothy Paun, and Julie Ruth for their advice and support.

\section{REFERENCES}

Baron, Reuben M., \& Kenny, David A. (1986). The moderator-mediator variable distinction in social psychological research: Conceptual, strategic, and statistical considerations. Journal of Personality and Social Psychology, 51, 1173-1182.

Bem, Daryl J. (1972). Self-perception theory. In Leonard Berkowitz (Ed.), Advances in experimental psychology (Vol. 6, pp. 1-62). New York: Academic.
Bower, Gordon H. (1972). Mental imagery and associative learning. In Lee Gregg (Ed.), Cognition in learning and memory (pp. 51-88). New York: Wiley.

Brehm, John M. (1966). A theory of psychological reactance. New York: Academic.

Calder, Bobby J., \& Staw, Barry M. (1975). Self-perception of intrinsic and extrinsic motivation. Journal of Personality and Social Psychology, 31, 599-605.

Cameron, Judy, \& Pierce, W. David. (1994). Reinforcement, reward, and intrinsic motivation: A meta-analysis. Review of Educational Research, 64, 363-423.

Dahl, Darren, Gorn, Gerald J., \& Weinberg, Charles B. (1997). Marketing, safer sex, and condom acquisition. In M. Goldberg, M. Fishbein, \& S. Middlestat (Eds.), Social marketing: Theoretical and practical perspectives (pp. 169-185). Mahwah, NJ: Lawrence Erlbaum Associates, Inc.

deCharms, Richard. (1968). Personal causation. New York: Academic.

Deci, Edward L. (1971). Effects of externally mediated rewards on intrinsic motivation. Journal of Personality and Social Psychology, 18, 105-115.

Deci, Edward L., \& Ryan, Richard M. (1985). Intrinsic motivation and self-determination in human behavior. New York: Plenum.

Diamond, William D., \& Loewy, Ben Z. (1991). Effects of probabilistic rewards on recycling attitudes and behavior. Journal of Applied Social Psychology, 21, 1590-1607.

Dodson, Joe A., Tybout, Alice M., \& Sternthal, Brian. (1978). Impact of deals and deal retraction on brand switching. Journal of Marketing Research, 15, 72-81.

Eagly, Alice, \& Chaiken, Shelly. (1993). The psychology of attitudes. Forth Worth, TX: Harcourt Brace.

Eisenberger, Robert, \& Cameron, Judy. (1996). Detrimental effects of reward: Reality or myth? American Psychologist, 51(11), 1153-1166.

Eisenberger, Robert, Pierce, W. David, \& Cameron, Judy. (1999). Effects of reward on positive motivation-Negative, neutral, and positive: Comment on Deci, Koestner, and Ryan (1999). Psychological Bulletin, 125, 677-691.

Fazio, Russell H., Powell, Martha C., \& Williams, Carol J. (1989). The role of attitude accessibility in the attitude-to-behavior process. Journal of Consumer Research, 16, 280-288.

Fischhoff, Baruch. (1975). Hindsight is not equal to foresight: The effect of outcome knowledge on judgment under uncertainty. Journal of Experimental Psychology: Human Perception and Performance, 1, 288-299.

Gorn, Gerald J., Goldberg, Marvin E., \& Basu, Kunal . (1993). Mood, awareness, and product evaluation. Journal of Consumer Psychology, 2, 237-256.

Gouldner, Alvin W. (1960). The norm of reciprocity: A preliminary statement. American Sociological Review, 25, 161-178.

Greenwald, Anthony G., Leipe, Michael R., Pratkanis, Anthony R., \& Baumgardner, Michael H. (1986). Under what conditions does theory obstruct research progress? Psychological Review, 93, 216-229.

Hannah, Darlene B., \& Sternthal, Brian. (1984). Detecting and explaining the sleeper effect. Journal of Consumer Research, 11, 632-642.

Hansen, Robert A. (1980). A self-perception interpretation of the effect of monetary and nonmonetary incentives on mail survey respondent behavior. Journal of Marketing Research, 17, 77-83.

Harackiewicz, Judith M. (1979). The effects of reward contingency and performance feedback on intrinsic motivation. Journal of Personality and Social Psychology, 37, 1352-1363.

Hitt, Dawn D., Marriott, Richard G., \& Esser, James K. (1992). Effects of delayed rewards and task interest on intrinsic motivation. Basic \& Applied Social Psychology, 13, 405-414.

Isen, Alice M., Clark, Margaret, Shalker, Thomas E., \& Karp, Lynn. (1978). Affect, accessibility of material in memory, and behavior: A cognitive loop? Journal of Personality and Social Psychology, 36, 1-12.

Kelley, Harold H. (1972). Attribution in social interaction. In Edward E. Jones, David E. Kanouse, Harold H. Kelley, Richard E. Nisbett, Stuart Valins, \& Bernard Weiner (Eds.), Attribution: Perceiving 
the causes of behavior (pp. 1-26). Morristown, NJ: General Learning Press.

Kisielius, Jolita, \& Sternthal, Brian. (1984). Detecting and explaining vividness effects in attitudinal judgments. Journal of Marketing Research, 21, 54-64.

Kruglanski, Arie W., Riter, Aviah, Amitai, Asher, Margolin, Bath-Shevah, Shabtai, Leorah, \& Zaksh, Daliah. (1975). Can money enhance intrinsic motivation?: A test of the content-consequenc e hypothesis. Journal of Personality and Social Psychology, 31, 744-750.

Lepper, Mark R. (1998). A whole much less than the sum of its parts. American Psychologist, 53, 675-676.

Lepper, Mark R., Greene, David, \& Nisbett, Richard E. (1973). Undermining children's intrinsic interest with extrinsic reward. Journal of Personality and Social Psychology, 28, 129-137.

Mavis, Brian E., \& Stoffelmayr, Bertram. (1994). Multidimensional evaluation of monetary incentive strategies for weight control. The Psychological Record, 44, 239-252.

Maxwell, Scott E., \& Delaney, Harold D. (1990). Designing experiments and analyzing data. Pacific Grove, CA: Brooks/Cole.

Moran, William P., Nelson, Karen, Wofford, James L., Velez, Ramon, \& Case, L. Douglas. (1996). Increasing influenza immunization among high-risk patients: Education or financial incentive? The American Journal of Medicine, 101, 612-620.

NCH Nuworld Marketing Limited. (1999). Worldwide coupon distribution \& redemption trends. Lincolnshire, IL: Author.

Neter, John, Wasserman, William, \& Kutner, Michael H. (1990). Applied linear statistical models. Burr Ridge, IL: Irwin.

Newman, Joan, \& Layton, Bruce D. (1984). Overjustification: A self-perception perspective. Personality and Social Psychology Bulletin, 10, 419-425.

Perreault Jr., William D., \& Leigh, Laurence E. (1989). Reliability of nominal data based on qualitative judgments. Journal of Marketing Research, 26, 135-148.

Pittman, Thane S., Davey, Margaret E., Alafat, Kimberly A., Wetherill, Kathryn V., \& Kramer, Nancy A. (1980). Informational versus controlling verbal rewards. Personality and Social Psychology Bulletin, 6, 228-233.

Rogers, Tim N., Kuiper, Nicholas, \& Kirker, William. (1977). Self-reference and the encoding of personal information. Journal of Personality \& Social Psychology, 35, 677-688.
Rosenfield, David, Folger, Robert, \& Adelman, Harold F. (1980). When rewards reflect competence: A qualification of the overjustification effect. Journal of Personality and Social Psychology, 39, 368-376.

Ross, Michael. (1975). Salience of reward and intrinsic motivation. Journal of Personality and Social Psychology, 32, 245-254.

Ryan, Richard M., Mims, Valerie, \& Koestner, Richard. (1983). Relation of reward contingency and interpersonal context to intrinsic motivation: A review and test using cognitive evaluation theory. Journal of Personal ity and Social Psychology, 45, 736-750.

Scott, Carol A. (1976). The effects of trial and incentives on repeat purchase behavior. Journal of Marketing Research, 13, 263-269.

Scott, Carol A., \& Yalch, Richard F. (1978). A test of the self-perception explanation of the effects of rewards on intrinsic interest. Journal of Experimental Social Psychology, 14, 180-192.

Scott, Carol A., \& Yalch, Richard F. (1980). Consumer response to initial product trial: A Bayesian analysis. Journal of Consumer Research, 7, 32-41.

Shimp, Terence A., Hyatt, Eva M., \& Snyder, David J. (1991). A critical appraisal of demand artifacts in consumer research. Journal of Consumer Research, 18, 273-283.

Tang, Shu Hua, \& Hall, Vernon C. (1995). The overjustification effect: A meta-analysis. Applied Cognitive Psychology, 9, 365-404.

Thibaut, J., \& Reicken, H. (1955). Some determinants and consequences of the perception of social causality. Journal of Personality, 24, 113-133.

Tybout, Alice M., \& Scott, Carol A. (1983). Availability of well-defined internal knowledge and the attitude formation process: Information aggregation versus self-perception. Journal of Personality and Social Psychology, 44, 474-491.

Tybout, Alice M., Sternthal, Brian, \& Calder, Bobby J. (1983). Information availability as a determinant of multiple request effectiveness. Journal of Marketing Research, 20, 280-290.

Witmer, Jill F., \& Geller, E. Scott. (1976). Facilitating paper recycling: Effects of prompts, raffles, and contests. Journal of Applied Behavior Analysis, 9, 315-322.

Wood, Wendy. (1982). Retrieval of attitude-relevant information from memory: Effects on susceptibility to persuasion and on intrinsic motivation. Journal of Personality and Social Psychology, 42, 798-810.

Wright, Peter. (1980). Message-evoke d thoughts: Persuasion research using thought verbalizations. Journal of Consumer Research, 7, 151-175. 